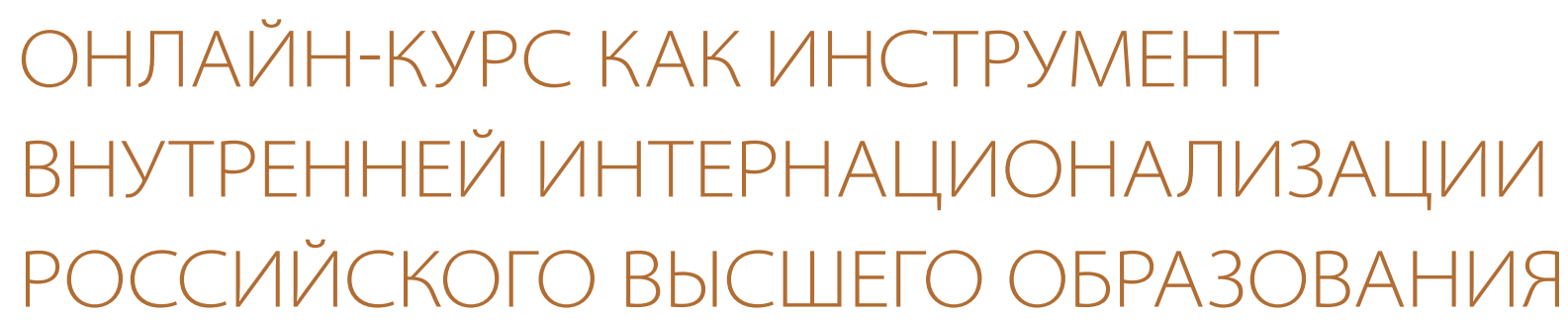

\title{
ONLINE COURSE AS A TOOL OF INTERNAL INTERNATIONALIZATION IN RUSSIAN HIGHER EDUCATION
}

\section{Копусь Татьяна Леонидовна}

Доцент Департамента языковой подготовки, Финансовый университет при Правительстве Российской Федерации, кандидат филологических наук E-mail: TLKopus@fa.ru

\section{Климова Ирина Иосифовна}

Профессор Департамента языковой подготовки, Финансовый университет при Правительстве Российской Федерации, кандидат филологических наук

E-mail: IIKlimova@fa.ru

Аннотация. Статья посвящена проблеме реализации практики внутренней интернационализации в системе российского высшего образования в формате онлайн-курса. Рассматриваются вопросы интернационализации курса как одного из направлений внутренней интернационализации. Авторы представляют опыт апробации онлайн-курса «Межкультурная деловая коммуникация»,

\section{Kopus Tatiana L.}

Assistant Professor at the Department of Foreign Languages, Financial University under the Government of the Russian Federation, PhD in Linguistics

E-mail:TLKopus@fa.ru

\section{Klimova Irina I.}

Professor at the Department of Foreign Languages, Financial University under the Government of the Russian Federation, PhD in Linguistics

E-mail:IIKlimova@fa.ru

Abstract. The article is devoted to the implementation of internal internationalization in Russian higher education through online course. The article is focused on internationalizing the course considered as one of the possible ways of internal internationalization. The authors present their experience of approbation of the "Intercultural Business Communication" online course,

(๔ Копусь Т. Л., Климова И. И., 2020 
разработанного с целью формирования и развития межкультурной коммуникативной компетенции в международных группах студентов-бакалавров. Целью апробации являлось изучение эффективности применения обучения в международных группах студентовбакалавров в формате онлайн-курса, ранее не использованного в образовательном процессе, определение оптимальных условий для последующей реализации данного формата. В исследовании применялся количественный и качественный анализ обратной связи, метод анкетирования обучающихся, сбор данных по результатам прохождения курса. Раскрываются методические решения по управлению онлайнкурсом, по организации интерактивной части курса.

Ключевые слова: онлайн-курс, внутренняя интернационализация, интернационализация дисциплины, межкультурная деловая коммуникация, межкультурная коммуникация, обучение в международных группах. designed to build and develop intercultural communication competence in international groups of undergraduate students. The aim of approbation was to understand the effectiveness of training in international groups of undergraduate students in the format of an online course that was not previously used in the educational process, as well as to determine the optimal conditions for the subsequent implementation of this format. The methods of research were: the quantitative and qualitative analysis of feedback, the method of questioning students, data collection on the results of the course. Methodical decisions on management of the online course, on the organization of the interactive part of the course are revealed.

\author{
Keywords: online course, internal \\ internationalization, internationalization of the \\ course, intercultural business communication, \\ intercultural communication, training in \\ international groups.
}

Процессы глобализации ставят принципиально новые задачи перед системами высшего образования во всем мире. В процессе обучения выпускники современных университетов должны быть готовы эффективно работать в условиях глобальной конкуренции, профессиональной мобильности, в составах международных коллективов и команд.

Одним из способов сформировать и развить такие компетенции у выпускников является внутренняя интернационализация (далее - ВИ) высших учебных заведений. Вопрос о разработке стратегии интернационализации российских вузов во всех областях деятельности (обучение, научно-исследовательская деятельность, администрирование, послевузовское образование) стоит на повестке дня, в этой связи предлагается уделять внимание культурной интеграции иностранных учащихся, организации курсов по изучению иностранных языков и межкультурного взаимодействия [1].

В рамках данной статьи речь пойдет о направлениях и задачах ВИ в области учебной деятельности, таких как реализация учебного процесса в интернациональных учебных группах, интернационализация дисциплин (далее - ИД), введение в учебный процесс интерактивных методов с использованием информационно-коммуникационных технологий, а также обеспечение владения навыками деловой коммуникации. 
Термин «внутренняя интернационализация» (internal internationalisation) находится в процессе становления в научном дискурсе и используется параллельно с целым рядом схожих терминов: «домашняя» интернационализация (internationalisation at home) [2], интернационализация образовательной программы, интернационализация учебного плана (internationalisation of the curriculum) [3], всеобъемлющая интернационализация (comprehensive internationalisation) [4], интернационализация кампуса (internationalisation of the campus) [5]. Наибольшей степенью схожести обладают термины «внутренняя интернационализация» и «домашняя» интернационализация», подчеркивающие важность создания международного измерения в условиях собственного учебного заведения, без участия в зарубежных программах академической мобильности.

Выбор термина «внутренняя интернационализация» объясняется сугубо стилистическими предпочтениями. Понимание термина «интернационализация образовательной программы» нередко рассматривается широко: как предоставление возможностей для мобильности и как разработка программы для иностранных студентов, реализуемой на английском языке, и как проектирование совместной программы, планируемой к реализации в партнерстве с зарубежным университетом. Однако решающее значение «интернационализация образовательной программы» имеет в условиях внутреннего обучения, подчеркивая необходимость охвата всех студентов, а не только мобильного менышинства, обеспечивая основу для поддержки интернационализации преподавания и обучения, а также фокусируясь на местных возможностях межкультурного обучения.

По мнению А. А. Муравьевой, смыслоразличительным признаком между понятиями «внутренняя интернационализация» и «интернационализация учебной программы» является соотношение «общее - частное». ВИ - более общее понятие (сродни родовому понятию), а образовательные программы - понятие видовое, то есть более специфическое по отношению к ВИ. В конечном счете, программы являются ключевым средством формирования требуемых компетенций для общества знаний и для жизни в глобальном обществе [6, с. 129].

Вслед за Б. Лиск под внутренней интернационализацией будет пониматься процесс, направленный на интеграцию в образовательную программу (для всех студентов, а не только иностранных) международного и межкультурного измерения, с использованием для этого средств формального и внеаудиторного обучения [7, с. 207]. Таким образом, ВИ отличается широтой, охватывая все многообразие видов образовательной деятельности, реализуемой вузом: преподавательскую деятельность и учебно-образовательную деятельность студентов, то есть сам процесс приобретения ими знаний, навыков и умений, внеаудиторную деятельность, связь с местными культурными/этническими профессиональными группами, исследовательскую или научную деятельность, интернационализацию кампуса, а также и способы их формализации: интернационализацию учебных планов, программ, курсов [7].

В прикладном аспекте интернационализация образовательной программы состоит из интернационализации отдельных дисциплин, что, в свою очередь, включает внедрение международного или межкультурного компонента в содержание дисциплины, преподавательскую деятельность, учебную деятельность студента и текущий, итоговый контроль за результатами [8]. К способам интернационализации курса относят различные инструменты: включение в материалы курса трудов зарубежных исследователей с целью сравнительно-сопоставительного анализа, международных тематических теоретических 
и практических исследований, международных кейсов, реализация учебного процесса в учебных группах, состоящих из представителей разных культур.

К преподаванию дисциплины подключают преподавателей из зарубежных вузов. Практикуются разные форматы участия обучающихся в международных образовательных проектах. Для оценивания работ студентов привлекаются представители зарубежных экспертных сообществ, а также такие форматы, как взаимопроверка работ одногруппниками по критериям, предлагаемым преподавателем, с тем условием, что авторы проекта и проверяющие принадлежат разным культурам. Реализовать предлагаемые способы интернационализации дисциплины становится возможным при возможностях цифрового обучения [9; 10]. Технологические решения обеспечивают равный доступ к возможностям интернационализации для всех студентов вуза.

С ростом интереса к возможностям, предоставляемым развитием ИКТ и онлайнобучением, Финансовый университет при Правительстве РФ присоединился к экспериментам в сфере онлайн-курсов. С этой целью была создана Открытая онлайн-академия (Open Online Academy), где на данный момент представлено 28 онлайн-курсов. Они интегрированы в учебный процесс, позволяя модифицировать формы и методы обучения. В 2018-2019 учебном году Департамент языковой подготовки Финансового университета создал и апробировал онлайн-курс «Межкультурная деловая коммуникация» (на английском языке), реализуемый в рамках направлений подготовки для уровня бакалавриата, в том числе с целью реализации стратегии интернационализации дисциплин. Согласно учебному плану университета, дисциплина «Межкультурная деловая коммуникация» способствует формированию и развитию универсальных компетенций «Коммуникация» (способен осуществлять деловую коммуникацию в устной и письменной формах на государственном языке Российской Федерации и иностранном(ых) языках), и «Межкультурное взаимодействие» (способен воспринимать межкультурное разнообразие общества в социально-историческом, этическом и философском контекстах) (ФГОС 3++), а также компетенциям: способность к коммуникации в устной и письменной формах на русском и иностранном языках для решения задач межличностного и межкультурного взаимодействия, способность применять знания иностранного языка на уровне, достаточном для межличностного общения, учебной и профессиональной деятельности.

Традиционно дисциплина «Межкультурная деловая коммуникация» преподавалась как курс по выбору для контингента студентов, обучающихся по профилю «Мировые финансы», «Международные экономические отношения». Обучение строилось в виде развития продуктивных и рецептивных навыков коммуникации: чтения текстов по тематике курса и профилю направления, дискуссий, ролевых игр, решения кейсов, посвященных проблемам межкультурной коммуникации. Важно отметить, что в аспекте проектирования реализация курса «Межкультурная деловая коммуникация» (на английском языке) в онлайн-формате была нацелена на отработку основ межкультурной коммуникации в плане теоретической части курса для начинающих, а не практической и продвинутой ступени, что обусловило структуру и дизайн элементов курса. Курс предлагался студентам второго года обучения. В записи видеолекций участвовал преподаватель, являющийся представителем британской культуры. Курс был открыт для регистрации и обучения студентов университета в течение 11 недель. 
Онлайн-курс представляет собой четыре темы.

Тема 1. Культура как ключ к конкурентоспособности. Работа в международных компаниях. Коммуникация с зарубежными партнерами. Европейский и азиатский стили общения.

Тема 2. Культурные бизнес-модели. Западная бизнес-модель. Восточная бизнес-модель.

Тема 3. Культурные проблемы слияний и поглощений. Международные слияния и поглощения. Удачные и неудачные слияния и поглощения.

Тема 4. Работа за рубежом: проблемы и преимущества. Управление международными командами. Опыт работы в международной компании как преимущество в карьере.

Каждая тема состоит из двух видеолекций с последующим выполнением контрольных заданий, домашних заданий и дополнительных учебных материалов. Промежуточная аттестация представляла собой контрольные задания в форме теста с множественным выбором в конще каждой темы. По завершении изучения четырех тем курса студентам предлагалось выполнить итоговый тест с множественным выбором. Итоговая оценка включала результаты четырех контрольных тестов по каждой теме, а также итоговую оценку по результатам итогового теста, охватывающего материалы всего курса. Четыре контрольных теста составляли в сумме максимум 40\% от общего конечного результата, в то время как итоговый тест соответствовал 60\%. При наборе 50\% и более дисциплина засчитывалась студентам как освоенная.

Домашнее задание представляло собой дискуссионный форум, построенный вокруг одного открытого вопроса, связанного с темой. Дискуссия была интерактивной частью онлайн-курса. Онлайн-инструкторы уделяли особое внимание модерированию и управлению этой частью курса. Участие в обсуждении не имело оценочного компонента, но управлялось инструкциями. Учащиеся и команда курса использовали обсуждения курса для выполнения заданий, обмена мнениями, рассмотрения различных точек зрения и вопросов. В дискуссии предлагалась трехуровневая иерархическая модель интерактивного взаимодействия:

1. Пост, инициирующая реплика, первый уровень взаимодействия. Целью создания поста являлось открытие новой темы для обсуждения. Участникам предлагалось высказать свою точку зрения или поделиться своим опытом. Часть постов были сформулированы инструкторами как открытые вопросы, чтобы начать разговор. Обучающимся было дано задание инициировать не менее 1 поста.

2. Реагирующая реплика, второй уровень взаимодействия. Реагирующая реплика это ответ-реакция на инициирующую реплику. Обучающимся было предложено ответить по крайней мере трем участникам.

3. Комментарий, третий уровень взаимодействия. Имеется в виду комментарий участника на реагирующую реплику. Этот уровень взаимодействия не управлялся инструкторами и не включал инструкций.

Студенты были мотивированы к активному участию в онлайн-дискуссии. Количественный и качественный анализ веток обсуждений показал, что студенты предпочитали общаться с преподавателями, а не вступать в дискуссии со своими сверстниками. Возникновение третьего уровня взаимодействия составило около 20\% от количества всех взаимодействий.

Поскольку тестовая часть курса оценивалась автоматически программой, то работа инструкторов курса заключалась в модерации дискуссии. Обучение проходило в условиях культурного разнообразия студентов, участвующих в прохождении курса: 
Великобритания, Монголия, Вьетнам, Франция, КНР, Замбия, Южная Корея и др. Эти иностранные студенты проходили обучение в Финансовом университете по программам обмена в течение семестра или входили в контингент студентов по основным программам.

Наибольший интерес вызвали вопросы, касающиеся актуальности и адекватности индексов культурного измерения в теории Г. Хофстеде и классификация культур Э. Холла; комментарии, приводимые представителями разных культур, наглядно демонстрировали различие образцов поведения в одинаковых коммуникативных деловых ситуациях. Удовлетворенность инструкторов курса вызвал факт естественности и необходимости условий и целей использования английского языка в интернациональной среде как инструмента общения, тогда как условия и цели использования английского языка в традиционных группах, состоящих на 100\% из русскоговорящих студентов, искусственны.

Курс предлагался к изучению как майнор два раза в осеннем и в весеннем семестрах 2018-2019 учебного года. Единственным ограничением являлся уровень владения языком - не ниже В1. Трудоемкость дисциплины составила 3 зачетных единицы, формой итоговой аттестации заявлен зачет. Первый набор на 20\% состоял из представителей разных культур. Во втором наборе на представителей других культур приходилось 23\% от общего количества обучающихся. Важно отметить, что студентам предоставлялся выбор формата прохождения дисциплины: онлайн-курс или традиционный формат. В результате устного опроса на первой очной встрече с инструкторами выяснилось, что ни один студент не имеет опыта обучения в онлайн-формате в рамках очной формы обучения в университете. Если при осеннем (первом) наборе $30 \%$ согласились пройти обучение в формате онлайн, то в весеннем (втором) наборе таких студентов стало 80\%. Результаты повторного опроса после окончания осеннего (первого) курса показали, что если бы студентам дали второй шанс выбирать, то уже 85\% хотели бы пройти курс в режиме онлайн.

В качестве дискуссии хотелось бы отметить, что видимый, ощутимый рост количества студентов, желающих обучаться онлайн, не следует интерпретировать только с одной стороны: как рост доверия к данному формату, как более удобную форму прохождения курса без посещения занятий. Однако важно признание и другой стороны. Это понимание того факта, что предлагаемый тест по выбору после темы, четко ограниченной материалами курса, - значительно более простой способ контроля материала, чем в аудитории. Нужно также принимать во внимание невозможность контроля со стороны преподавателей этического аспекта выполнения заданий.

По итогам академической успеваемости 98\% студентам дисциплина была зачтена, из них 89\% набрали 80\% и более, что свидетельствует о высоком качестве успеваемости слушателей курса. $2 \%$ слушателей показали неудовлетворительные результатов из-за полного отрыва от учебного процесса.

В конце курса студентам предлагалась анкета с вопросами, позволяющими осознать и оценить приобретенный опыт. Анкета включала 3 блока вопросов, нацеленных на оценку: 1) элементов курса, 2) опыта обучения посредством онлайн-курса, 3) опыта обучения в международной группе. Анкета состояла из открытого и закрытого типа вопросов. Удовлетворенность элементами курса и тематикой отметило подавляющее болышинство обучающихся (97\%). Опыт апробации изучения дисциплины в формате онлайн-курса показывает, 
что к преимуществам изучения дисциплины в формате онлайн-курса, отмечаемым самими студентами в анкете, можно отнести (в порядке убывания по популярности ответа):

1. Возможность учиться в своем собственном темпе в любое время (95\%).

2. Объективность и прозрачность промежуточной и итоговой аттестации по предмету (87\%).

3. Подходящий, привычный и удобный формат - работа с планшета, смартфона (65\%).

4. Отсутствие давления в виде конкурентной среды, в виде фигуры преподавателя (43\%). Сложность прохождения курса вызвало:

1. Неумение равномерно распределять учебный материал (86\%).

2. Отсутствие самодисциплины, нарушение сроков сдачи заданий (51\%).

3. Ощущение, что не к кому обратиться за помощью, чувство беспомощности и отсутствие обратной связи, когда инструктор не реагировал на вопросы (34\%).

4. Неудобство писать то, что проще и быстрее было бы сказать (12\%).

Преимущества и недостатки обучения в формате онлайн-курсов со студентами очной формы обучения остаются открытой темой для обсуждения в научном педагогическом сообществе, учитывая противоречивые выводы исследователей о целесообразности онлайн-курсов. С одной стороны, обсуждается возможность стопроцентной замены лекций в региональных вузах онлайн-курсами с видеолекциями признанных специалистов по предмету. С другой стороны, признается факт переноса традиционного формата лекции в аудитории в режим видеолекции, что мало говорит в пользу эффективности данного формата, не считается трансформацией существующей модели, не вызывает энтузиазма у преподавателей, особенно учитывая трудоемкость подготовки качественного видеоконтента.

Особый отклик вызвал факт возможности изучения особенностей межкультурной деловой культуры непосредственно от представителя определенной культуры, то есть возможность выдвинуть гипотезу об образце коммуникативного поведения представителями той или ной культуры и получить подтверждение или корректировку от представителей этих культур, также обучающихся на этом курсе. Среди других ответов, положительно оценивающих опыт взаимодействия, были развитие осознания собственного знания английского языка и других студентов, интерес к практическому обучению в международном классе, возможность «вживую» познакомиться с другими культурами и другими способами жизни и мышления, увидеть мир другими глазами.

Практическая часть курса «Межкультурная деловая коммуникация» предполагает интерактивный режим общения. Сегодня коммуникативные навыки, наряду с критическими навыками, креативностью, сотрудничеством, относят к одной из четырех ключевых компетенций XXI в., необходимой для современных выпускников. Университеты являются не только учебным заведением, в котором передаются знания, они представляют собой социальную структуру и создают социальную среду. Занятия в аудитории создают социальный контекст общения.

Поскольку основной задачей данного курса являлось освоение теоретических основ межкультурной деловой коммуникации, то отсутствие социального присутствия участников и вследствие этого невозможность создать условия аутентичной устной коммуникации мы бы отнесли к проблемам, которые должен решить следующий онлайн-курс, 
нацеленный на тренировку практических навыков межкультурной коммуникации в смешанном формате.

Реализация курса «Межкультурная деловая коммуникация» (на английском языке) в онлайн-формате позволила охватить всех желающих, обучающихся на всех программах и направлениях для уровня бакалавриата, решая проблему неравенства и ограничения в доступе к интересующим курсам среди студентов одного вуза, обучающихся на более и менее престижных программах. Так, помимо студентов, обучающихся по профилю «Мировые финансы», «Международные экономические отношения», данный курс был выбран студентами, обучающимися по профилирующим направлениям: туризм, логистика, информационная безопасность, управление персоналом, социология, что вызывало сложности для очного, офлайн-формата обучения.

Итак, апробация онлайн-курса подчеркнула важность внутренней интернационализации, результаты которой могут быть доступны всем студентам, а не только мобильному меньшинству. Как известно специалистам, внутренняя интернационализация университета позволяет решить проблему острой необходимости качественных изменений. С точки зрения решения образовательной задачи мы создали платформу для формирования опыта межкультурного взаимодействия студентов на английском языке, основанного на их личном опыте через вовлечение в дискуссии в международных группах, через решение кейсов и их последующее обсуждение, анализ в общем пространстве курса.

\section{Список литературы}

1. Богуславский М. В., Неборский Е. В. Стратегические тенденции развития системы высшего образования в Российской Федерации // Гуманитарные исследования Центральной России. 2017. № 2. С. 7-20.

2. Beelen J., Jones E. Redefining Internationalization at Home // The European Higher Education Area. Between Critical Reflections and Future Policies. Springer, Cham. 2015. P. 59-72.

3. Leask B. Internationalising the Curriculum. Abingdon: Routledge, 2015. 210 p.

4. Hudzik J. K., McCarthy J. S. Leading Comprehensive Internationalization: Strategy and Tactics for Action. Washington DC: NAFSA, 2012. 32 p.

5. Интернационализация кампуса // Сайт Ассоциации международных деятелей образования (NAFSA). URL: https://www.nafsa.org/about/about-nafsa/nafsacampus-internationalization (дата обращения: 04.11.2019).

6. Муравъева А. А., Олейникова О. Н., Викторова А. О. Интернационализация образовательных программ как ядро внутренней интернационализации образования // Вестник ВГУ. 2017. № 4. С. 154-157.

7. Leask B. Using formal and informal curricula to improve interactions between home and international students // Journal of Studies in International Education. 2009. Vol. 13, No. 2. P. 205-221.

8. Leask B. Internationalisation of the curriculum and the Disciplines // Journal of Studies in International Education Special Issue. 2013. Vol. 17, No. 2. P. 103-118.

9. Международное высшее образование. ВШЭ, 2016. № 83.40 с. 
10. Императивы интернационализации / отв. ред. М. В. Ларионова, О. В. Перфильева. М.: Логос, 2013. 420 с.

\section{References}

1. Boguslavskiy M. V., Neborskiy E. V. Strategicheskie tendentsii razvitiya sistemy vysshego obrazovaniya v Rossiyskoy Federatsii. Gumanitarnye issledovaniya Tsentralnoy Rossii. 2017, No. 2, pp. 7-20.

2. Beelen J., Jones E. Redefining Internationalization at Home. In: The European Higher Education Area. Between Critical Reflections and Future Policies. Springer, Cham. 2015. Pp. 59-72.

3. Leask B. Internationalising the Curriculum. Abingdon: Routledge, 2015. 210 p.

4. Hudzik J. K., McCarthy J. S. Leading Comprehensive Internationalization: Strategy and Tactics for Action. Washington DC: NAFSA, 2012. 32 p.

5. Internatsionalizatsiya kampusa. Available at: https://www.nafsa.org/about/aboutnafsa/nafsa-campus-internationalization (accessed: 04.11.2019).

6. Muravyeva A. A., Oleynikova O. N., Viktorova A. O. Internatsionalizatsiya obrazovatelnykh programm kak yadro vnutrenney internatsionalizatsii obrazovaniya. Vestnik VGU. 2017, No. 4, pp. 154-157.

7. Leask B. Using formal and informal curricula to improve interactions between home and international students. Journal of Studies in International Education. 2009, Vol. 13, No. 2, pp. 205-221.

8. Leask B. Internationalisation of the curriculum and the Disciplines. Journal of Studies in International Education Special Issue. 2013, Vol. 17, No. 2, pp. 103-118.

9. Mezhdunarodnoe vysshee obrazovanie. VShE. 2016, No. 83. 40 p.

10. Larionova M. V., Perfilieva O. V. (eds.) Imperativy internatsionalizatsii. Moscow: Logos, 2013. 420 p.

\section{Интернет-журнал \\ «Проблемы современного образования» \\ 2020, № 3}

Статья поступила в редакциию 11.11.2019

The article was received on 11.11.2019 